\title{
Matching words to concepts in two languages: A test of the concept mediation model of bilingual representation
}

\author{
ROBERT DUFOUR \\ Swarthmore College, Swarthmore, Pennsylvania \\ and \\ JUDITH F. KROLL \\ Pennsylvania State University, University Park, Pennsylavnia
}

\begin{abstract}
A categorization paradigm was used to investigate the relations between lexical and conceptual connections in bilingual memory. Fifty-one more fluent and less fluent English-French bilinguals viewed category names (e.g., vegetable) and then decided whether a target word (e.g., peas) was a member of that category. The category names and target words appeared in both English and French across experimental conditions. Because category matching requires access to conceptual memory, only relatively fluent bilinguals, who are able to directly access meaning for their second language, were expected to be able to use category information across languages. The performance of lessfluent bilinguals was expected to reflect reliance on lexical-level connections between languages, requiring translation of second-language words. The results provided evidence for concept mediation by more-fluent bilinguals, because categorization latencies were independent of the language of the category name. However, the performance of less-fluent bilinguals indicated that they did not follow a simple lexical translation strategy. Instead, these subjects were faster at categorizing words in both languages when the language of the category name matched the language of the target word, suggesting that they were able to access limited conceptual information from the second language. A model of the development of concept mediation during second language acquisition is described.
\end{abstract}

A central question in research on bilingual memory representation concerns how a bilingual's two languages are stored in memory. Does each language possess its own memory store or do languages share a single representational system? Recent research on bilingual memory suggests that both alternatives are correct, but at different levels of representation (e.g., Durgunoglu \& Roediger, 1987; Potter, So, von Eckhardt, \& Feldman, 1984; Snodgrass, 1984). At the lexical level, words in each language appear to be stored independently, but at the conceptual level, words in each language appear to

This research was conducted while the first author was supported by a National Institute of Mental Health Training Grant MH16745-12 awarded to the Department of Psychology at the University of Massachusetts, Amherst. This work was supported in part by NSF Grants DBS 92-11863 and GER-9350115 to J. F. Kroll. We thank Catherine Elsinger, Mary Jo Rattermann, Aruna Sankaranarayanan, and especially Alexandra Sholl, Annette de Groot, A. Y. Durgunoglu, Brian Ross, and an anonymous reviewer for helpful comments; we also thank Alison Fowler for her assistance with data collection. A preliminary report of this study was presented at the Thirteenth Annual Second Language Research Forum, University of Pittsburgh, March 1993. Correspondence should be addressed to R. Dufour, Department of Psychology, Swarthmore College, 500 College Avenue, Swarthmore, PA 19081-1397 (e-mail: rdufour1@cc.swarthmore.edu) or to J. F. Kroll, Department of Psychology, Pennsylvania State University, University Park, PA, 16802 (e-mail: jfk7@cac.psu.edu). access a common semantic representation. Thus, there is a hierarchical arrangement of words and concepts, with separation at the lexical level but with connections to a semantic system that is shared across languages. ${ }^{1}$

This hierarchical model, in and of itself, does not specify the form of connections between the bilingual's two languages. It is possible that the two languages are interconnected at the lexical level, or through a common conceptual representation. Potter et al. (1984) tested these theoretical alternatives, referred to respectively as word association and concept mediation, by comparing the performance of more-fluent and less-fluent bilinguals on picture naming and translation in their second language (L2). Because picture naming is thought to require concept mediation (see, e.g., Potter \& Faulconer, 1975), the demonstration that translation resembles picture naming would suggest that translation also engages conceptual processing. Potter et al. (1984) showed that translation did resemble picture naming and argued that concept mediation was the basic form of interlanguage connection in bilingual memory because all subjects, regardless of their level of L2 fluency, appeared able to mediate conceptually.

More recent studies have shown that Potter et al.'s (1984) conclusions hold only for individuals beyond an early point in second-language learning (e.g., Chen \& Leung, 1989; Kroll \& Curley, 1988). In adults, early 


\section{Lexical Links}

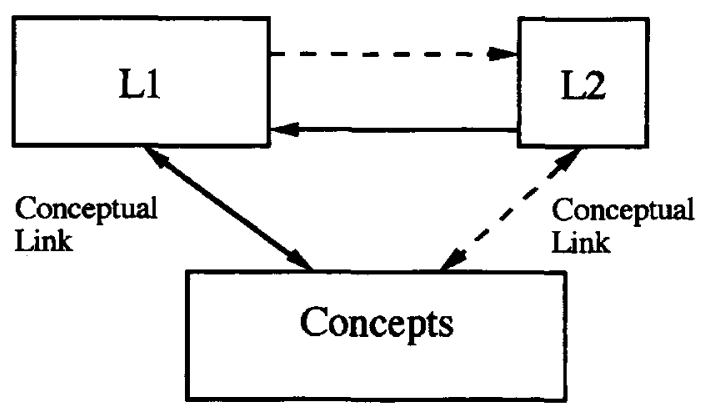

Figure 1. The revised hierarchical model. From "Category Interference in Translation and Picture Naming," by J. F. Kroll and E. Stewart, 1994, Journal of Memory \& Language, 33, p. 158. Copyright 1994 by Academic Press. Adapted by permission.

stages in the acquisition of second-language vocabulary appear to be characterized by reliance on the first language (L1). That is, during the initial phase of L2 acquisition, individuals seem to rely on associations between words in their two languages. With greater proficiency in the second language, they become able to access concepts directly without first-language involvement.

Kroll and her colleagues (Kroll \& Sholl, 1992; Kroll et al., 1992; Kroll \& Stewart, 1990, 1994) have proposed a revised version of the hierarchical model to account for the consequences of this developmental change from words to concepts with increasing fluency. The revised model is shown in Figure 1. The model assumes that the shift in second-language learning from words to concepts creates an asymmetry in the form of connections between a more fluent bilingual's two languages. Because the second language relies initially on the first language for the purpose of gaining access to meaning, there are residual lexical-level associations that are hypothesized to be stronger from $\mathrm{L} 2$ to $\mathrm{L} 1$ than from $\mathrm{L} 1$ to L2. L1, however, accesses concepts more effectively than does L2, and thus the strength of the conceptual links for each language is also assumed to vary as a function of fluency.

\section{Evidence for the Revised Hierarchical Model}

One source of evidence for the model shown in Figure 1 is provided by translation experiments. Subjects are asked to translate from their first language into their second language (L1 to L2) or from their second into their first (L2 to L1). Translation latencies are reliably faster in the L2 to $\mathrm{L} 1$ direction than in the $\mathrm{L} 1$ to $\mathrm{L} 2 \mathrm{di}$ rection (Kroll \& Curley, 1988; Kroll \& Stewart, 1990, 1994; Sánchez-Casas, Davis, \& García-Albea, 1992; Sholl, 1993 ). ${ }^{2}$ This translation asymmetry is predicted by the revised hierarchical model. According to the model, translation from $\mathrm{L} 1$ to $\mathrm{L} 2$ requires conceptual access, whereas translation from $\mathrm{L} 2$ to $\mathrm{L} 1$ can be accomplished directly on the basis of the lexical link between words in the two languages. Once L1 activates conceptual memory, conceptual activation must then direct re- trieval of L2 lexical representations before a single L2 candidate can be chosen. Conceptual access is less direct, and therefore $\mathrm{L} 1$ to $\mathrm{L} 2$ translation takes longer than L2 to L1 translation. An analogous asymmetry has been reported in cross-language semantic priming studies, such that L1 primes L2 but L2 produces very little priming of Ll (e.g., Altarriba, 1990; Keatley, Spinks, \& de Gelder, 1994; Tzelgov \& Eben-Ezra, 1992).

Further support for the model is provided by the fact that the translation asymmetry is greater for less-fluent bilinguals than for more-fluent bilinguals (Kroll, 1993; Kroll, Dufour, Sholl, \& Roufca, 1993). In early phases of second language learning, less-fluent individuals show a large asymmetry between the two routes of translation. Specifically, translation from $\mathrm{L} 1$ to $\mathrm{L} 2$ is especially long and prone to errors (or failure to retrieve the appropriate translation). Translation from $\mathrm{L} 2$ to $\mathrm{L} 1$ is faster and more accurate than translation from L1 to L2. More-fluent bilinguals are also relatively efficient at translating from L2 to L1. However, the more-fluent bilinguals are faster and more accurate than the lessfluent bilinguals in translating from L1 to L2. That is, translation performance from $\mathrm{L} 1$ to $\mathrm{L} 2$ becomes faster and more accurate as subjects become more fluent, whereas translation performance from $\mathrm{L} 2$ to $\mathrm{L} 1$ is similar for more- and less-fluent subjects. The change in $\mathrm{L} 1$ to L2 translation can be attributed to the ability of the more-fluent bilinguals to conceptually mediate the second language. As subjects become more proficient in $\mathrm{L} 2$, they become increasingly able to use conceptual activation to direct retrieval of words from the $\mathrm{L} 2$ lexicon.

Other aspects of the performance of bilinguals at different stages of L2 acquisition also provide support for the revised model. For more-fluent bilinguals, L1 to L2 translation performance is affected by the semantic context in which translation is performed, whereas $\mathrm{L} 2$ to $\mathrm{L} 1$ translations are not. Kroll and Stewart $(1990,1994)$ found that relatively fluent bilinguals showed interference when translating lists of words that were semantically categorized. However, category interference was observed only when subjects translated from L1 to L2; translation from $\mathrm{L} 2$ to $\mathrm{L} 1$ was unaffected by the semantic context of the list in which translation occurred. This difference is consistent with the proposal that conceptual activation occurs during L1 to L2 translation but not during $\mathrm{L} 2$ to $\mathrm{L} 1$ translation.

Additional evidence that more-fluent bilinguals are able to conceptually mediate the second language, but that less-fluent bilinguals are not, comes from a recent translation recognition study (Talamas \& Kroll, 1993). In translation recognition (de Groot, 1992) subjects must decide whether two words are translation equivalents. Talamas and Kroll manipulated the relations between English/Spanish word pairs so that some false translation pairs shared form (e.g., man-hombre was a correct translation pair but man-hambre, where hambre means hunger, was a form-related pair) and other pairs shared meaning (e.g., man-mujer, where mujer means woman, was a semantically related pair). They found that rela- 
tively fluent English-Spanish bilinguals produced significant interference (i.e., longer response latencies than did an unrelated control) for the semantically related pairs, but not for the form-related pairs. Less-fluent English-Spanish bilinguals produced significant interference for the form-related pairs but not for the semantically related pairs. This pattern is consistent with the claim that less-fluent bilinguals rely initially on lexical form and only later are able to access meaning directly for L2 words.

Taken together, these findings suggest that morefluent bilinguals can effectively access lexical and conceptual connections between their two languages. Lessfluent bilinguals, however, appear to rely heavily on lexical associations from $\mathrm{L} 2$ to $\mathrm{L} 1$. What is unclear from past research is how less-fluent bilinguals eventually become able to mediate L2 conceptually. The goal of the present experiment was to compare the performance of more- and less-fluent bilinguals (native English speakers who varied in their proficiency in French) in a context in which conceptual information would be available and/or mandatory for the purpose of the task. If lessfluent bilinguals cannot access conceptual information directly from the second language, then any task that requires them to do so should produce long and error-prone responses that also reflect attempts to resort to firstlanguage mediation. In the present experiment, subjects performed a categorization task in which they had to decide whether a target exemplar was a member of a previously named superordinate category. We predicted that less-fluent subjects would rely on a strategy of word association or lexical mediation that would distinguish their performance from the performance of more-fluent subjects in L2. We found that less-fluent subjects did not simply resort to a translation strategy when forced to access conceptual information via $\mathrm{L} 2$. Their performance was, however, different from that of more-fluent bilinguals and indicates that less-fluent bilinguals have some limited access to meaning from their second language.

\section{Semantic Categorization}

In semantic categorization experiments, subjects are presented with the name of a superordinate category (e.g., vegetable) and must decide whether a subsequent target word (e.g., peas) is an exemplar of the preceding superordinate category. In another version of this task, two category exemplars are presented and the subject must decide whether they belong to the same superordinate category. Categorization has been used extensively to examine the architecture of semantic memory (e.g., Rosch, 1975; Smith, Shoben, \& Rips, 1974). Moreover, many past studies have shown that access to semantic information is equally available for both pictures and the words that name them (e.g., Potter \& Faulconer, 1975; Rosch, 1975). Although there is some debate about why pictures are sometimes categorized more rapidly than words, the results of recent experiments suggest that words and pictures access a similar semantic represen- tation (see, e.g., Job, Rumiati, \& Lotto, 1992; Siple, Walls, \& Miller, 1985).

As in the results for word and picture categorization, previous research on semantic categorization in two languages indicates that fluent bilinguals can categorize equally well within and across their two languages (Caramazza \& Brones, 1980; Potter et al., 1984; Shanon, 1982 ). This evidence has been taken to support the view that the fluent bilingual's two languages are conceptually mediated by a semantic representation common to both languages. However, there are a number of methodological problems with the past studies that may have created a similar pattern of results for the within- and crosslanguage conditions, regardless of whether the subjects were conceptually mediating. The most problematic feature of the past experiments is the relatively long interval that occurred between the presentation of the superordinate category name and target exemplars. For example, Caramazza and Brones (Experiment 1) used a 2 -sec interval between the category and target words. During a long interstimulus interval, subjects have the opportunity to translate either or both of the words. Thus subjects might demonstrate similar ease in categorizing in both languages, because they may have performed the task in their preferred language via translation. In another experiment, both words were presented simultaneously. The simultaneous presentation of category word and target exemplar may also be problematic, because the simultaneous format may induce decision processes that also take advantage of translation (see Neely, 1990, for analogous arguments about the lexical decision task). Hence, the previous categorization studies are not conclusive about whether more-fluent bilinguals can directly conceptually mediate $L 2$, and past studies have not systematically examined the performance of lessfluent bilinguals in this task.

According to the revised hierarchical model, if lessfluent bilinguals have greater difficulty in using L2 to access conceptual representations, they should find semantic categorization in L2 an extremely difficult task. We predicted that the more-fluent bilinguals would be faster and more accurate at categorizing than the lessfluent bilinguals because the more-fluent subjects can access concepts directly from $\mathrm{L} 2$, as well as recognize L2 words more rapidly than the less-fluent subjects can. Less-fluent bilinguals, however, should not only be slower because they will have to rely on translation strategies to gain access to concepts in L2, but should also produce a distinct pattern of categorization performance. The time to categorize target words in L2 should depend on the form of the information available in L2 and the time available to process the relation between the category name and the target word.

To attempt to assess the role of processing time, we also manipulated the stimulus onset asynchrony (SOA) between the presentation of the category name and the target exemplar. Because even subjects within a fluency group vary in their proficiency in L2, it is difficult to 
make precise assumptions regarding the time course of processing. In the present experiment, subjects were tested in the categorization task with either a $300-\mathrm{msec}$ SOA or a $650-\mathrm{msec}$ SOA. Although our goal was not to make specific claims about each of the SOA values, we could make a general prediction that at the longer SOA there would be more of an opportunity for translation to occur. If less-fluent bilinguals must translate $\mathrm{L} 2$ words into $\mathrm{L} 1$ to perform the categorization task, then the manipulation of SOA would be expected to influence the time available for translation and would thus affect translation performance, particularly when L2 category names and target words were presented. We further assumed that a translation strategy would be more difficult to use in the shorter SOA condition and thus would lead to more errors for subjects unable to mediate $\mathrm{L} 2$ conceptually.

If subjects are able to mediate L2 conceptually, the language of the category names should not affect categorization, because target exemplars in both languages would access the same underlying memory representation. However, if subjects are relying on a translation strategy, then presenting the category name in L1 should produce faster categorization for L1 targets than should presenting the category name in $\mathrm{L} 2$, because the latter will require at least one word to be translated on each trial. Furthermore, the condition in which both the category name and the target word are presented in L2 should be the slowest to categorize, because both words would have to be translated in order to access their respective meanings.

\section{METHOD}

\section{Design and Materials}

English-French bilinguals were asked to categorize words in each language following category names in each language. The resulting four conditions are illustrated in Table 1 . In the withinlanguage conditions, both the category name and the target word were presented in the same language. In the cross-language conditions, the category names were presented in one language and the target exemplars were presented in the other language.

Subjects were tested in all of the language conditions in separate blocks within one experimental session. The order of presentation for the four conditions was randomized following a Latin square design. There were eight test categories (birds, clothing, fruit, furniture, tools, vegetables, vehicles, and weapons ) and three filler categories (flowers, trees, and toys). Each of the test

Table 1

Within- and Cross-Language Conditions for the Categorization Task

\begin{tabular}{|c|c|c|c|c|}
\hline \multicolumn{2}{|c|}{ Language } & \multirow[b]{2}{*}{ Category } & \multicolumn{2}{|c|}{ Target Category } \\
\hline of Category & of Target & & Same (Yes) & Different (No) \\
\hline \multicolumn{5}{|c|}{ Within-Language Conditions } \\
\hline $\begin{array}{l}\text { English } \\
\text { French }\end{array}$ & $\begin{array}{l}\text { English } \\
\text { French }\end{array}$ & $\begin{array}{l}\text { vegetable } \\
\text { meuble }\end{array}$ & $\begin{array}{l}\text { peas } \\
\text { chaise }\end{array}$ & $\begin{array}{l}\text { dagger } \\
\text { pomme }\end{array}$ \\
\hline \multicolumn{5}{|c|}{ Cross-Language Conditions } \\
\hline $\begin{array}{l}\text { English } \\
\text { French }\end{array}$ & $\begin{array}{l}\text { French } \\
\text { English }\end{array}$ & $\begin{array}{l}\text { weapon } \\
\text { oiseau }\end{array}$ & $\begin{array}{l}\text { fusil } \\
\text { robin }\end{array}$ & $\begin{array}{l}\text { jupe } \\
\text { boat }\end{array}$ \\
\hline
\end{tabular}

categories included 16 target words. The materials were divided into two versions, with the assignment of versions to the sameand different-category conditions counterbalanced across subjects. All target items were ranked as high typical exemplars for their respective categories in English, using Rosch's prototype ratings (Rosch, 1975). The test categories, target words, and their respective typicality ratings and word frequencies are listed in the Appendix.

Each block comprised 38 trials, 32 test trials, and 6 filler trials. Half the trials required the subject to respond "yes," and half the trials required the subject to respond "no." Within a block, each category name was presented four times, twice with samecategory exemplars and twice with different-category exemplars. Each block of the experiment contained category-target pairs drawn from each of the eight test categories. The design of the study called for 32 subjects: 16 less-fluent and 16 more-fluent bilinguals, with half of each group being tested with an SOA of $300 \mathrm{msec}$ and the other half being tested with an SOA of $650 \mathrm{msec}$.

\section{Procedure}

Category names and target words were presented in succession on the screen of an IBM XT computer. A two-choice button box attached to the computer was used to register the subject's response. Subjects held the button box with both hands. The left thumb rested on the "yes" button, and the right thumb rested on the "no" button. A trial consisted of a fixation point $(+)$ presented for $300 \mathrm{msec}$, followed by the category name presented for $250 \mathrm{msec}$. In the short SOA condition, the target word was presented $300 \mathrm{msec}$ following the onset of the category name; in the long SOA condition, the target word was presented $650 \mathrm{msec}$ following the onset of the category name. In both cases, the target word was presented for $300 \mathrm{msec}$. Subjects were instructed to indicate, as quickly and as accurately as possible, whether or not the target word was a member the category denoted by the previously presented word. Their tesponse times (RTs) to indicate a "yes" or "no" response were measured to the nearest millisecond. At the end of the testing session, the subjects completed a questionnaire that assessed their second language experience. After completing the questionnaire, the subjects were fully debriefed. The experimental session lasted 30-45 min.

The subjects' proficiency in L2 could only be approximated prior to test. Thus, 32 subjects were tested according to the counterbalanced design, but the final assessment of subjects' fluency ultimately led to a partially balanced design. An additional group of 19 subjects were tested to ensure that a sufficiently large sample of more- and less-fluent subjects would be represented in each of the cells of the experiment. Data for all 51 subjects were analyzed.

\section{Subjects}

Fifty-one English-French bilingual subjects at varying levels of proficiency in French were recruited at Mount Holyoke College and the University of Massachusetts at Amherst. The subjects either received class credit or were paid for their participation. Performance fluency was assessed for "yes" responses in the categorization task in such a way that only subjects whose mean accuracy in both French target conditions was $75 \%$ or greater were considered relatively fluent. All other subjects were considered less fluent. Using this criterion, the less-fluent group comprised 24 subjects: 14 tested in the short SOA condition and 10 tested in the long SOA condition. The more-fluent group comprised 27 subjects: 14 tested in the short SOA condition and 13 tested in the long SOA condition.

An analysis of questionnaire responses was performed to compare the second-language experience and self-ratings of the moreand less-fluent subjects and to determine whether the division of subjects into groups corresponded with their actual language experience. A profile of each of the subject groups is presented in Table 2. 


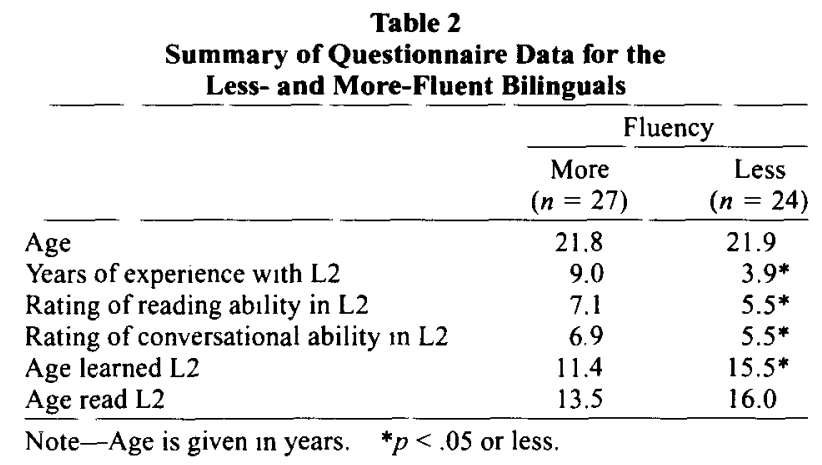

These data indicate that the two groups were similar in age at testing $[t(49)<1, p>.10]$, but differed significantly on the number of years of experience with $\operatorname{L} 2[t(49)=-3.91, p<.001]$ and on the age at which they began learning $L 2[t(49)=2.39, p<.05]$ The difference in the age at which they began reading $\mathrm{L} 2$ was marginally significant $[t(49)=1.61, p<.06]$. Furthermore, the two groups differed in the ratings that they assigned to their L2 fluency (on a 10-point scale, with 10 being the most fluent) in reading and writing $[t(49)=-3.19, p<.01]$ and in conversational skills $[t(49)=-2.13, p<.05]$. The fact that the mean age of learning L2 was 11.4 years for the more fluent group and 15.5 years for the less fluent group indicates that both groups of subjects acquired the second language past early childhood. ${ }^{3}$ Overall, however, the questionnaire data show that the two groups were indeed distinct from one another in terms of their experience and proficiency in French.

Because each subject's fluency was determined following his/ her assignment to one of the SOA conditions, it was also important to check that the average French accuracy of subjects at each level of fluency was equivalent for the two SOA conditions. A comparison of mean French accuracy showed that this was the case: accuracy for the less-fluent subjects was $65 \%$ for both the short and long SOA groups; accuracy for the more-fluent subjects was $83 \%$ in both SOA conditions.

\section{RESULTS}

The same ("yes") and the different ("no") category responses were analyzed separately. All correct RTs of less than $300 \mathrm{msec}$ and more than $4,000 \mathrm{msec}$ were considered outliers. In addition, scores greater than 2.5 standard deviations above the mean of the remaining correct RTs were also identified as outliers. With these procedures, less than $3 \%$ of the RTs were rejected from the final analyses.

Analyses of variance were performed on mean categorization RTs for correct responses and proportion accuracy in each condition in order to examine the effects of fluency (less and more fluent in L2), SOA (300 or $650 \mathrm{msec}$ ), language of the category name (English or French), and language of the target word (English and French). Fluency and SOA were between-subject factors, and language of the category name and language of the target word were within-subject factors.

Analyses of variance were also performed on the mean categorization RTs by items. Some missing cells were present in this item analysis, in part because the less-fluent subjects occasionally failed to produce a cor- rect response for some items. Missing values were replaced by using a conservative procedure in which the mean for that item averaged over both the language of the category name and the language of the target word was substituted for the missing value.

If subjects are able to conceptually mediate $\mathrm{L} 2$, the language of the category name should not affect categorization, because target exemplars in both languages would access the same semantic memory representation. However, if subjects must resort to lexical mediation to access meaning for $\mathrm{L} 2$, any condition in which L2 category names or target words are presented should produce longer categorization latencies in comparison with those obtained in the comparable Ll conditions.

\section{Same-Category Conditions ("Yes")}

The SOA manipulation produced a main effect only in the analysis by items $\left[F_{1}(1,47)=2.21, M S_{\mathrm{e}}=109,416\right.$, $\left.p>.10 ; F_{2}(1,121)=28.78, M S_{\mathrm{e}}=46,658, p<.001\right]$. The item analysis indicated that subjects in the 300 -msec SOA condition were, on the average, $52 \mathrm{msec}$ faster than subjects in the $650-\mathrm{msec}$ SOA condition. There were no significant interactions between SOA and other variables in either the subject or the item analyses. Likewise, in the analysis of the accuracy data, there was no significant main effect of SOA $\left[F(1,47)<1, M S_{\mathrm{e}}=.006\right]$, nor were there interactions with other variables.

The RT data are shown in Figure 2 for all conditions collapsed across SOA. The top graph shows data for the more-fluent subjects and the bottom graph shows data for the less-fluent subjects. In each case, mean categorization RTs are shown as a function of the language of the category name and the language of the target word. A comparison of these graphs shows clearly that the two groups of bilinguals were affected differently by the language of the category name. Consistent with the predictions, the more-fluent subjects appeared to be uninfluenced by the language of category name, although they took somewhat longer in categorizing French as opposed to English target words. In contrast, the less-fluent subjects showed a clear effect of the relation between the language of the category name and the language of the target word. The three-way interaction between fluency, language of the category name, and language of the target words was significant in the analysis by subjects $\left[F_{1}(1,47)=9.32, M S_{\mathrm{e}}=14,731, p<.005\right]$ and items $\left[F_{2}(1,121)=5.72, M S_{\mathrm{e}}=51,608, p<.05\right]$. The same interaction was not significant in the accuracy analysis $\left[F(1,47)=2.17, M S_{\mathrm{e}}=.007, p>.10\right]$. Planned comparisons were performed on subject means using $t$ tests. To minimize the probability of a Type I error, we used the Bonferroni procedure for estimating the appropriate alpha value for the series of contrasts of interest (see Kirk, 1982, for a description of this procedure). For the more-fluent subjects, as the graph indicates, there was no significant difference between the mean categorization latencies for the English-English $(M=783 \mathrm{msec})$ and the French-English $(M=788 \mathrm{msec})$ conditions [ $t(26)$ $<1, p\rangle .10]$, and no difference was found between the 

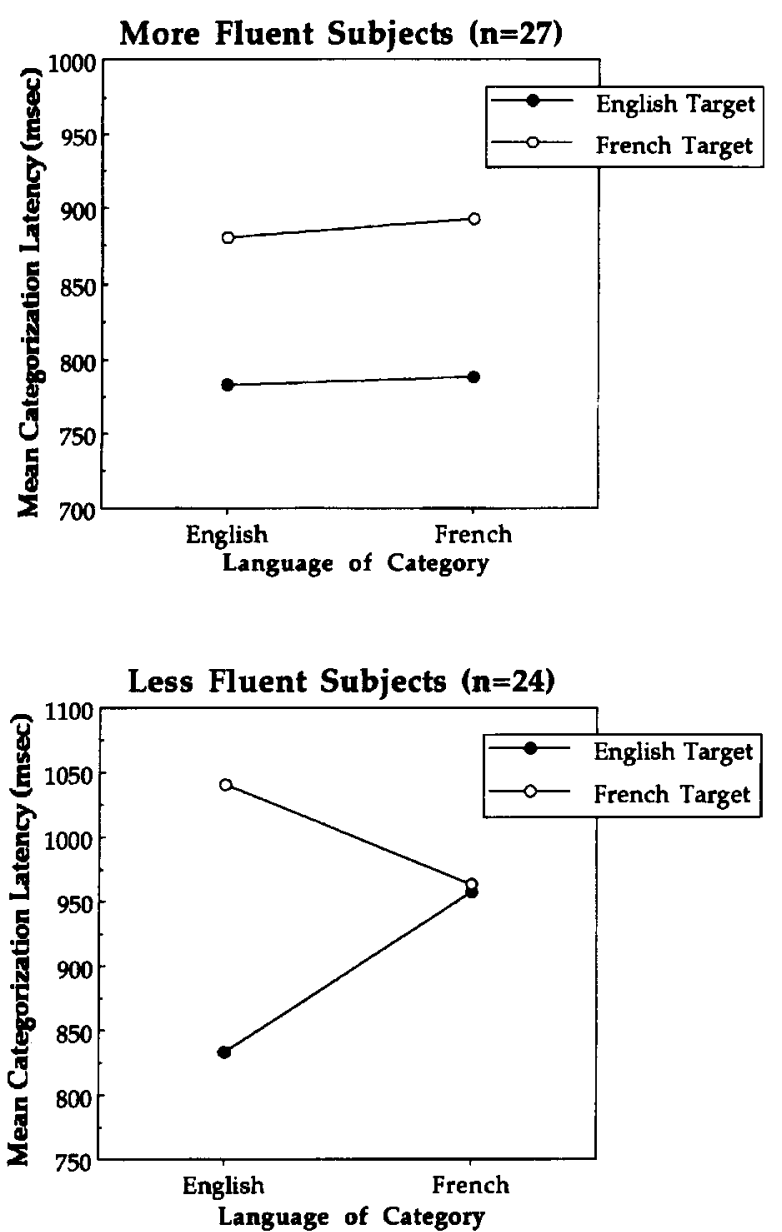

Figure 2. Mean categorization latencies (in milliseconds) for "yes" responses, as a function of the language of the category name and the language of the target word. Data for more-fluent subjects are shown on the top graph, and data for the less-fluent subjects are shown in the bottom graph.

English-French $(M=881 \mathrm{msec})$ and the French-French $(M=893 \mathrm{msec})$ conditions $[t(26)<1, p>.10]$. However, for the less-fluent subjects, the difference between the mean categorization latencies for the English-English $(M=833 \mathrm{msec})$ and French-English $(M=958 \mathrm{msec})$ conditions was significant $[t(23)=-3.60, p<.006]$, and the difference between the English-French $(M=$ $1,041 \mathrm{msec})$ and the French-French $(M=964 \mathrm{msec})$ conditions approached significance when the Bonferroni correction was used $[t(23)=2.05, p=.02]$ but was clearly significant by a conventional $t$ test. Furthermore, the patterns of results obtained for each of the SOA conditions were identical to one another and similar to the one presented above. The means for each of the four stimulus conditions are presented in Table 3 for the two SOA conditions.

The RT analysis also showed significant main effects of fluency $\left[F_{1}(1,47)=5.80, M S_{\mathrm{e}}=109,416, p<.05\right.$; $\left.F_{2}(1,121)=105.49, M S_{\mathrm{e}}=120,522, p<.001\right]$. This main effect was also obtained in the analysis performed on accuracy data $\left[F(1,47)=118.17, M S_{\mathrm{e}}=.006, p<\right.$ $.001]$. However, because accuracy for French target words was used as a criterion to select the two subject groups, this main effect is neither surprising nor of interest. Main effects of the language of the target word were also obtained $\left[F_{1}(1,47)=40.65, M S_{\mathrm{e}}=13,347\right.$, $\left.p<.001 ; F_{2}(1,121)=45.58, M S_{\mathrm{e}}=58,676, p<.001\right]$. This last result was also found in the analysis of proportion accuracy $\left[F(1,47)=224.90, M S_{\mathrm{e}}=.005, p<.001\right]$. Overall, the subjects were faster and more accurate in categorizing target words in English than in French, a result that is to be expected for all English-dominant subjects. There was also a significant interaction of language of the category name and target word $\left[F_{1}(1,47)=\right.$ $8.02, M S_{\mathrm{e}}=14,731, p<.01 ; F_{2}(1,121)=12.57, M S_{\mathrm{e}}=$ $49,851, p<.001]$. No other main effects or interactions were significant in any of the analyses that we have reported.

For the more-fluent bilinguals, targets were categorized more rapidly in $\mathrm{L} 1$ than in $\mathrm{L} 2$, suggesting that although these subjects were relatively fluent, they were not balanced bilinguals. However, the striking result for the more-fluent subjects is that the speed of categorization within each language was unaffected by the language of the category name. Thus, categorization of both English and French targets was equally rapid for both the within- and the cross-language conditions. This pattern of results supports the claim that more-fluent bilinguals are able to mediate their second language conceptually. If the language of the category name has no effect on categorization latencies, especially when the SOA conditions limit the opportunities for translation, it is most parsimonious to assume that each language activates similar category information in conceptual memory. These results also replicate those of the previous bilingual categorization studies providing evidence for concept mediation (Caramazza \& Brones, 1980; Potter et al., 1984; Shanon, 1982) and go beyond the past results in demonstrating that the same pattern can be obtained at a relatively short SOA.

The results for the less-fluent bilinguals are more complex. Their performance on the English targets indicates that they were much faster in the within-language condition than in the cross-language condition. This pattern suggests either that the less-fluent subjects had to translate the French category names before being able to correctly categorize the English target words, or that the process of accessing the concept for the French category words could not be completed prior to the presentation of the English target words. The results for the French target words are similar to the pattern for the English targets in that subjects were again faster in the within-language condition than in the cross-language condition. However, this result is surprising, because it suggests that the less-fluent subjects were not relying on a simple translation strategy. If these subjects were simply translating the French words into English, then decision latencies in the French-French condition should have been the longest of all, but they were not. In the 
Table 3

Same-Category Conditions ("Yes"), Mean Categorization Latencies

(RT, in Milliseconds), and Mean Proportion Accuracy for the Two Stimulus Onset Asynchrony (SOA) Conditions

\begin{tabular}{|c|c|c|c|c|c|c|c|c|}
\hline \multirow[b]{4}{*}{ Category } & \multicolumn{8}{|c|}{ Target } \\
\hline & \multicolumn{4}{|c|}{ 300-msec SOA } & \multicolumn{4}{|c|}{$650-\mathrm{msec} \mathrm{SOA}$} \\
\hline & \multicolumn{2}{|c|}{ English } & \multicolumn{2}{|c|}{ French } & \multicolumn{2}{|c|}{ English } & \multicolumn{2}{|c|}{ French } \\
\hline & RT & Accuracy & RT & Accuracy & RT & Accuracy & RT & Accuracy \\
\hline \multicolumn{9}{|c|}{ More-Fluent Subjects } \\
\hline English & 752 & .89 & 838 & .80 & 815 & .97 & 924 & .82 \\
\hline French & 738 & .90 & 832 & .86 & 837 & .90 & 954 & .84 \\
\hline \multicolumn{9}{|c|}{ Less-Fluent Subjects } \\
\hline English & 824 & .89 & 1008 & .68 & 843 & .87 & 1074 & .68 \\
\hline French & 938 & .86 & 933 & .63 & 978 & .80 & 994 & .62 \\
\hline
\end{tabular}

Discussion, we will return to this result in order to consider whether less-fluent bilinguals do have some limited capacity to mediate words in L2 conceptually. Overall, however, the difference in the pattern of results for the more- and less-fluent subjects supports the claim that, with increasing proficiency, there is an increasing ability to mediate second-language words conceptually.

\section{Different-Category Conditions ("No")}

Categorization, like other binary classification tasks, includes decision processes that potentially complicate the interpretation of the results (see Balota \& Chumbley, 1984 , and Seidenberg, Waters, Sanders, \& Langer, 1984, for related analyses of the lexical decision task). In particular, "no" responses are likely to be the result of a number of different processes. Whereas by answering "yes" a subject is indicating that the target item is a member of the previously named category, a "no" response can reflect at least three alternatives: (1) the target item is not a member of the previously named category, (2) the subject does not know if the target item is a member of the previously named category because he or she does not know the target item (e.g., that a thrush is a bird), or (3) the subject does not know the French word used to denote the category name or target word (e.g., that grive is the French translation of thrush). The third alternative may especially apply to less-fluent subjects who, by definition, are less proficient in L2. A particular consequence of this alternative may be to create a bias toward responding "no" when any uncertainty exists. The accuracy data appear to follow this pattern. Overall, subjects were much more accurate in the different-category ("no") condition than in the samecategory ("yes") condition $[t(50)=-6.14, p<.001]$. Because the presentation of specific items was counterbalanced across the "yes" and "no" conditions, the very same items appeared in both conditions for different subjects. Therefore the observed difference in accuracy cannot be attributed to a difference in difficulty between items in the two conditions.

The RT data for "no" responses are shown in Figure 3, collapsed across SOA. Just as in Figure 2 for the "yes" responses, the top graph shows the data for the morefluent subjects and the bottom graph shows the data for the less-fluent subjects. In each case, mean categorization RTs are shown as a function of the language of the category name and the language of the target word. A comparison of these graphs indicates that the two groups again produced different patterns of categorization data, although the differences are not as large as those shown in Figure 2 for the "yes" responses. The more-fluent subjects again produced a pattern that is consistent with the concept mediation pattern. Their RTs appear to have been uninfluenced by the language of the category name, although these subjects took longer, overall, to categorize French as opposed to English target words. In contrast, the less-fluent subjects show a clear effect of the relation between the language of the category name and the language of the target word. The three-way interaction between fluency, language of the category name, and language of the target words only approached significance $\left[F_{1}(1,47)=3.57, M S e=17,018, p=.06\right.$; $\left.F_{2}(1,121)=3.83, p=.052\right]$. The analysis on proportion accuracy was not significant $[F(1,47)<1]$. As for the "yes" responses, planned comparisons using $t$ tests were performed on the RT data. For the more-fluent subjects, as can be seen in Figure 3, there was no significant difference between the mean categorization latencies for the English-English $(M=838 \mathrm{msec})$ and the FrenchEnglish $(M=866 \mathrm{msec})$ conditions $[t(26)=-1.01, p>$ $.10]$, or between the English-French $(M=941 \mathrm{msec})$ and the French-French $(M=961 \mathrm{msec})$ conditions $[t(26)<1]$. However, for the less-fluent subjects, the difference between the "no" RTs for the EnglishEnglish $(M=880 \mathrm{msec})$ and the French-English $(M=$ $1,030 \mathrm{msec})$ conditions was significant $[t(23)=-3.57$, $p<.006$ ], while the difference between the EnglishFrench $(M=1,132 \mathrm{msec})$ and the French-French $(M=$ $1,132 \mathrm{msec})$ conditions was not significant $[t(23)<1]$.

For the "yes" responses, there was only a main effect of SOA in the item analysis. However, for the "no" responses, there was a significant effect of SOA in all three analyses [for RT, $F_{1}(1,47)=6.61, M S_{\mathrm{e}}=149,645$, $p<.05 ; F_{2}(1,121)=71.07, M S_{\mathrm{e}}=97,553, p<.001$; 

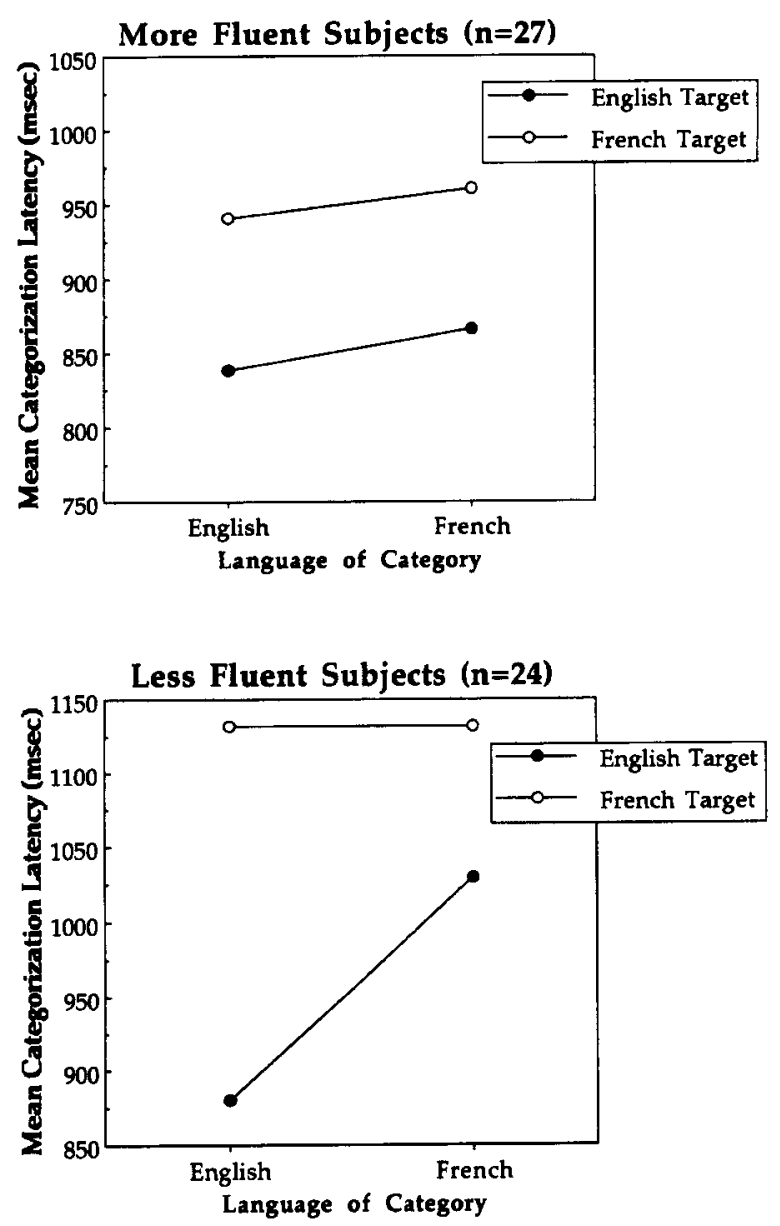

Figure 3. Mean categorization latencies (in milliseconds) for "no" responses, as a function of the language of the category name and the language of the target word. Data for more-fluent subjects are shown on the top graph, and data for the less-fluent subjects are shown in the bottom graph.

and accuracy, $\left.F(1,47)=5.99, M S_{\mathrm{e}}=.011, p<.05\right]$. The RT analyses for the "no" responses also yielded a significant three-way interaction of SOA, language of the category name, and language of the target words $\left[F_{1}(1,47)=4.17, M S_{\mathrm{e}}=17,018, p<.05 ; F_{2}(1,121)=\right.$
7.12, $\left.M S_{\mathrm{e}}=103,918, p<.01\right]$ and a significant interaction of SOA and language of the target words $\left[F_{1}(1,47)=\right.$ $4.62, M S_{\mathrm{e}}=16,490, p<.05 ; F_{2}(1,121)=18.24, M S_{\mathrm{e}}=$ $106,137, p<.001]$. The latter result was also obtained in the accuracy analysis $\left[F_{1}(1,47)=5.49, M S_{\mathrm{e}}=.006, p<\right.$ $.05]$. These effects of SOA indicate that the subjects were faster at responding "no" in the short SOA condition than in the long SOA condition. Furthermore, this was especially true when either the category or the target word was in English. Finally, the four-way interaction for the RT analyses was not significant $\left[F_{1}(1,47)=\right.$ $4.17, M S_{\mathrm{e}}=17,018, p>.10 ; F_{2}(1,121)=2.54, M S_{\mathrm{e}}=$ $143,312, p>.10]$; although it was significant for the accuracy analysis $\left[F(1,47)=5.04, M S_{\mathrm{e}}=.006, p<.05\right]$. The mean accuracy for the four-way interaction are presented in Table 4. The focus of this interaction is on the French target words for the less-fluent subjects. The less-fluent subjects were less accurate in responding "no" in the longer SOA condition. This result suggests that the less-fluent subjects did not benefit from longer presentation time of the target words. Finally, there were a number of additional significant results in these analyses. There were main effects of fluency, language of the category name, and language of the target words, as well as significant two-way interactions between fluency and language of the target words and between language of the category name and language of the target words. However, all of these results were qualified by the threeway interaction previously described.

Overall, the results for the different-category ("no") responses provide converging evidence that only the more-fluent subjects were able to conceptually mediate L2. The results for these subjects indicate that their "no" answers were unaffected by the language of the category name, suggesting that they are capable of conceptual mediation of both $\mathrm{L} 1$ and $\mathrm{L} 2$. Furthermore, the patterns for the "no" responses were similar to the patterns they produced for the "yes" responses except that their RTs were, on the average, approximately $62 \mathrm{msec}$ slower for the "no" responses. The results for the less-fluent subjects indicate that concept mediation of L2 did not occur for "no" responses. Although the interaction between the language of the category name and the language of

Table 4

Different-Category Conditions ("No") Mean Categorization Latencies

(RT, in Milliseconds) and Mean Proportion Accuracy for the Two Stimulus Onset Asynchrony (SOA) Conditions

\begin{tabular}{|c|c|c|c|c|c|c|c|c|}
\hline \multirow[b]{4}{*}{ Category } & \multicolumn{8}{|c|}{ Target } \\
\hline & \multicolumn{4}{|c|}{$300-\mathrm{msec} \mathrm{SOA}$} & \multicolumn{4}{|c|}{ 650-msec SOA } \\
\hline & \multicolumn{2}{|c|}{ English } & \multicolumn{2}{|c|}{ French } & \multicolumn{2}{|c|}{ English } & \multicolumn{2}{|c|}{ French } \\
\hline & RT & Accuracy & RT & Accuracy & RT & Accuracy & RT & Accuracy \\
\hline \multicolumn{9}{|c|}{ More-Fluent Subjects } \\
\hline English & 818 & .96 & 857 & 86 & 858 & .94 & 1025 & .86 \\
\hline French & 826 & .92 & 892 & .86 & 906 & .93 & 1029 & .83 \\
\hline \multicolumn{9}{|c|}{ Less-Fluent Subjects } \\
\hline English & 829 & 95 & 990 & .88 & 932 & .95 & 1273 & .73 \\
\hline French & 938 & .95 & 1068 & 82 & 1121 & .92 & 1199 & .75 \\
\hline
\end{tabular}


the target word was not as dramatic for "no" responses as for "yes" responses, there was still evidence for an effect of category language, at least for the English target words. As stated above, it is likely that the "no" responses, especially for the less-fluent subjects, were often based on a default strategy due to their level of uncertainty about the meaning of French target words. The fact that SOA interacted with the categorization conditions only for the "no" responses also suggests that the SOA, rather than conceptual access, influenced these decision processes.

\section{DISCUSSION}

The categorization performance of the more-fluent bilinguals replicated the results of previous studies on bilingual categorization that have reported no effect of language of the category name on the time to categorize words in each of the bilingual's languages (see, e.g., Caramazza \& Brones, 1980). However, the performance of the less-fluent bilinguals did not replicate this pattern. The results of the present experiment indicate that the less-fluent subjects were not only slower and less accurate than the more-fluent subjects, but they also produced a distinct pattern of within- and cross-language categorization. The more-fluent bilinguals were faster to categorize L1 targets than L2 targets, but for each target language, categorization was unaffected by the language of the category word. Because this result held, even when the SOA between the category name and the target word was brief, it suggests that the more-fluent bilinguals were able to conceptually mediate both of their languages. In addition, the fact that there was no effect of the language of the category name on the more-fluent subjects' performance is consistent with the claim that once bilinguals are able to mediate L 2 conceptually, it is the same conceptual representations that are accessed by each language, at least for the concrete nouns used in the present study.

The less fluent bilinguals' performance stands in contrast to the results for the more-fluent subjects, in that there were clear effects of the language of the category name as well as of the language of the target word. The less-fluent subjects were faster to categorize when the language of the category name matched the language of the target word. If these subjects had simply been translating the French words into English, this pattern should not have occurred, because the French-French condition should have required the most translation and therefore should have produced the longest RTs. The results for the less-fluent subjects thus failed to support the predictions of the word association model, because these subjects did not appear to use $\mathrm{L} 1$ to access concepts for $\mathrm{L} 2$ words. Furthermore, the fact that the pattern of categorization data for the less-fluent subjects was similar in both SOA conditions suggests that increasing the opportunity to translate did not substantially affect subjects' performance. Thus, although the less-fluent subjects produced a significantly different pattern of categorization data than did the more-fluent subjects, there was little in the present results to suggest that less-fluent subjects rely on a translation strategy.

\section{Categorizing Cognates: Using Lexical Form to Bypass Concept Mediation}

If less-fluent subjects do not access L2 concepts via the L1 lexicon, we need to consider how they do access L2 concepts when forced to use semantic information to perform the categorization task. One possibility is that less-fluent subjects use lexical form, when it is available, to bypass concept mediation. Because the materials used in the categorization experiment included words that were cognates in English and French (i.e., words that share aspects of lexical form and meaning), it is possible that the performance of the less-fluent bilinguals represents a mixture of trials on which they lexically mediated L2 and trials on which they used the correlated lexical form of $\mathrm{L} 2$ and $\mathrm{L} 1$ to activate $\mathrm{L} 1$ representations and their corresponding meaning. For example, when presented with the target word pigeon in French, the lessfluent subject can take advantage of the fact that pigeon is also the name of the bird in English, thus bypassing the necessity to use L2 to retrieve the word's meaning. Although there is some controversy in the literature concerning the way in which cognates are processed, there is agreement that cognate words in L2 can be translated more rapidly than noncognate words (e.g., de Groot, 1992; Kroll \& Stewart, 1994; Sánchez-Casas et al., 1992). There is also recent evidence suggesting that lessfluent bilinguals are particularly sensitive to the presence of cognates (Roufca, 1992). In the present experiment, activation of the cognate's lexical form in L1 would also constitute lexical mediation, but there would be little processing cost involved, because the subject would proceed as if the target were an L1 word. Thus, the less-fluent subjects' performance on the cognate targets would appear to be conceptually mediated because all the target words would functionally be in L1. However, the less-fluent subjects' performance on the noncognate targets would require standard lexical mediation. A post hoc analysis of the categorization data was performed to examine this possibility.

In a simple task, $37.7 \%$ of the target words used in the categorization experiment were judged to be cognates. Native English speakers $(n=15)$ who had no knowledge of French or Spanish as a second language were asked to guess the English translation of a series of French target words. French words that were correctly guessed by more than $50 \%$ of the subjects were considered to be cognates. All other words were considered to be noncognates. It was thus possible to compute separate means for cognate and noncognate targets. An initial comparison was performed to check that there were no confoundings between cognate status and target word frequency or category typicality. An analysis of word frequency and category typicality indicated that cognate and noncognate targets were, on the average, of similar frequency [ 18.2 and 21.2 per million, respectively; 
$t(119)<1]$ and similar typicality [1.71 and 1.83 out of 7 , respectively; $t(119)=-1.18, p>.10]$. An analysis of variance was then performed on subject means for the "yes" RT data as a function of fluency, language of the category name, language of the target word, and cognate status of the target. ${ }^{4}$ The data for the cognate-noncognate comparison is shown in Table 5. The important result is that, as in the overall analysis, there was a significant interaction between fluency, language of the category name, and language of the target word $\left[F(1,47)=8.64, M S_{\mathrm{e}}=\right.$ $34,207, p<.01]$, but no further interaction between this pattern and cognate status $[F(1,47)<1]$. For all subjects, categorization latencies were faster for cognates than for noncognates $\left[F(1,47)=30.8, M S_{\mathrm{e}}=15,523\right.$, $p<.001]$, but this main effect was qualified by an interaction showing that the cognate advantage occurred primarily when the target words were French $[F(1,47)=$ $\left.31.56, M S_{\mathrm{e}}=8,047, p<.001\right]$. Thus, both more- and lessfluent subjects were faster at categorizing French words when they were cognates; however, the pattern of results described in the main analyses also characterized performance for both cognate and noncognate target words. More-fluent subjects showed evidence for concept mediation because the language of the category name had no effect on categorization performance. Less-fluent subjects were again fastest when the language of the category name matched the language of the target word, regardless of whether the target word was a cognate or not.

A similar analysis of variance performed on the accuracy data for these conditions also showed that the cognate status of the target word was important only when the target appeared in French, the subjects' second language $\left[F(1,47)=35.62, M S_{\mathrm{e}}=.002, p<.001\right]$. There was also a marginally significant interaction between fluency and cognate status in the accuracy analysis $\left[F(1,47)=3.74, M S_{\mathrm{e}}=.002, p<.06\right]$, which is consistent with the notion that the less-fluent subjects benefit more from the presentation of cognates (see Table 5). The critical result, however, was that there was no interaction between cognate status and the overall patterns described for the more- and less-fluent subjects.
The analysis of cognate status suggests that lessfluent subjects were not using lexical form to bypass concept mediation. The pattern of categorization performance for more- and less-fluent subjects was similar for both cognate and noncognate target words. However, for both groups of subjects, there were clear advantages in speed and accuracy for cognates presented in the nondominant language. We consider the implications of these findings for models of bilingual representation later in the discussion.

\section{Reconsidering Concept Mediation}

The performance of the less-fluent subjects suggests that there may be costs associated with cross-language processing. Other recent studies have come to a similar conclusion for lexical decision (Grainger \& Beauvillain, 1987; Grainger \& O'Reagan, 1992) and for category matching (Hines, 1993). One possible reason for difficulty in cross-language processing may be that the cross-language conditions promote the activation of both lexical stores, and less-fluent bilinguals may not be able to properly inhibit the influence of the dominant language. In order to address the validity of this hypothesis, we consider an extension of the model described by Kroll and Stewart $(1990,1994)$ that may explain the apparent cross-language cost for less-fluent bilinguals.

Another explanation for the results we have presented for the less-fluent bilinguals is that these subjects do conceptually mediate $\mathrm{L} 2$, but perhaps in a more limited or restricted manner than the more-fluent bilinguals. As bilinguals become more proficient in $\mathrm{L} 2$, they become better able to mediate their access to L2 conceptually and to use L2 to retrieve meaning. Because it is unlikely that this process is entirely discrete (i.e., individuals do not wake up one morning suddenly able to mediate their second language conceptually), direct concept mediation of $\mathrm{L} 2$ must be acquired gradually, occurring earlier for more familiar words and concepts. Although this process may not proceed until some initial vocabulary is acquired for $L 2$, once that point is achieved, whether an individual lexically or conceptually mediates L2 may be a matter of degree that is deter-

Table 5

Mean Categorization Latencies (RT, in Milliseconds) and Mean Proportion Accuracy for "Yes" Responses for Cognate and Noncognate Target Items

Target

\begin{tabular}{|c|c|c|c|c|c|c|c|c|c|c|}
\hline \multirow[b]{4}{*}{ Category } & \multicolumn{9}{|c|}{ Target } & \multirow[b]{4}{*}{ Diff } \\
\hline & \multicolumn{4}{|c|}{ English } & & \multicolumn{4}{|c|}{ French } & \\
\hline & \multicolumn{2}{|c|}{ Cognate } & \multicolumn{2}{|c|}{ Noncognate } & \multirow[b]{2}{*}{ Diff. } & \multicolumn{2}{|c|}{ Cognate } & \multicolumn{2}{|c|}{ Noncognate } & \\
\hline & $\mathrm{RT}$ & Accuracy & RT & Accuracy & & RT & Accuracy & RT & Accuracy & \\
\hline \multicolumn{11}{|c|}{ More-Fluent Subjects } \\
\hline English & 796 & .95 & 774 & .91 & -22 & 840 & .89 & 932 & .77 & 92 \\
\hline French & 772 & .91 & 799 & .90 & 27 & 827 & .94 & 945 & .79 & 118 \\
\hline \multicolumn{11}{|c|}{ Less-Fluent Subjects } \\
\hline English & 821 & .86 & 841 & .87 & 20 & 970 & .84 & 1128 & .58 & 158 \\
\hline French & 931 & .84 & 982 & .82 & 51 & 902 & .81 & 1012 & .53 & 110 \\
\hline
\end{tabular}

Note - Diff $=$ difference score of noncognate RT - cognate RT. 
mined by their relative fluency in L2 and by the nature of the L2 materials. (See Kroll, 1993, for a discussion of how this process may occur for translation performance, and de Groot, 1993, for a discussion of the effects of word type on the form of interlingual connections.) For an adult second-language learner who has acquired L2 through classroom experience rather than by immersion in another culture, it is unlikely that new concepts are acquired as new second language words are learned. Instead, the task for the second-language learner is to learn how to map new L2 words onto old concepts. Furthermore, the patterns of activation generated by access to these old and familiar concepts may affect the ability of the second-language learner to access an individual concept in L2.

How do less-fluent bilinguals perform categorization if they only have some limited ability to mediate L 2 conceptually? Because the less-fluent subjects have a smaller L2 lexicon and know fewer category exemplars in the second language, it is possible that the presentation of an L2 category cue activates a small but welldefined set of conceptual representations in L2. In contrast, the presentation of an Ll category cue is more likely to activate a larger set of conceptual representations, creating a more diffuse pattern of activation that only partially overlaps with the smaller L 2 set. For example, presentation of the category name meuble to a less-fluent English-French bilingual may activate only the concepts of chaise, tapis, table, and étagère; presentation of the category name furniture would activate many more concepts than the four that are known in L2. Thus, the shared conceptual representations described by the revised hierarchical model are in fact not activated equally by both languages unless the individual achieves a state of relatively balanced bilingualism. This proposal maintains the assumption that at least some amodal concepts are shared across languages (e.g., for the concrete nouns used in the present experiment). However, the two languages are hypothesized to differ in the patterns of overall conceptual activation that they produce. That is, the size of the second-language lexicon may determine the degree to which conceptual representations linked to L2 can benefit from activation of shared elements in L1. When an individual is at an early stage of L2 acquisition, L2 words may activate a highly restricted set of concepts that form only a small subset of the category knowledge they have in Ll. Activating the entire known set of category exemplars via L1 may therefore be of little help and may actually inhibit the retrieval of concepts that are accessible from L2, because a large number of concepts that are unknown in L2 will also be activated.

As the individual becomes more fluent in $\mathrm{L} 2$, the size of the conceptual set activated by L2 will become larger and eventually approximate the set activated by $\mathrm{L} 1$. Once this occurs, the bilingual will be able to use L2 to access meaning directly and will also be able to mediate access from L1 to L2 by activating shared conceptual representations. Technically speaking, if a bilingual is able to use L2 to activate concepts without first language mediation, he/she is a concept mediator. However, the capacity to activate concepts from L2 may not be a sufficient condition for the ability to use concepts in general as a form of interlanguage connection. We have argued that the more-fluent subjects in the present study were concept mediators because they appeared able to use either L1 or L2 to access concepts in the other language. By comparison, the less-fluent subjects may have been able to retrieve concepts associated with $\mathrm{L} 2$ words, but they appeared unable to retrieve the same concepts when prompted by an $L 1$ category name.

The patterns of activation corresponding to the process of concept mediation that we have described are illustrated in Figure 4. The top figure shows the assumed representation for the more-fluent bilinguals. The large set at the conceptual level stands for a single firstlanguage-based category. The smaller set stands for a single second-language-based category. The smaller set stands for the same category represented by the larger set, but is second-language based. The difference in size is meant to represent graphically the fact that the category may not share all the concepts across the two languages. The filled units within the sets represent shared concepts; the unfilled units represent concepts that are accessible in L1 (in this case, English) only.

The illustration at the bottom of Figure 4 depicts the same representation for less-fluent bilinguals. When individuals are at an early stage of L2 learning, the size of the second-language-based category and the size of the L2 lexicon are assumed to be smaller than those for the more-fluent bilinguals. Furthermore, the connections between L2 words and concepts are weak, and only a few of the concepts in a given category or conceptual space are shared by the two languages. In the FrenchFrench condition, presentation of the category name in the second language will activate a limited set of conceptual representations for the less-fluent bilinguals. Since these subjects have a smaller L2 lexicon, presentation of a French target word will lead to a relatively fast categorization response: either the target has a match at the conceptual level or it does not (i.e., the subject does not know that word in L2). In the EnglishFrench condition, however, presentation of the category name in the first language will give rise to a wide pattern of activation at the conceptual level. This will have the effect of slowing the categorization response when the subject is presented with a French target, because the activation of concepts that do not correspond to known French words may create unhelpful cues that suggest that the subject should know that word (this is similar, for example, to a tip-of-the-tongue state). The widespread activation of concepts within a category when the category is named in the first language will thus create an inhibitory effect on the second language.

The French-English condition is likely to produce a pattern of activation that is limited at first to the conceptual representations associated with $\mathrm{L} 2$, and only later generalized to the conceptual representations that 
More Fluent Bilingual's Representation

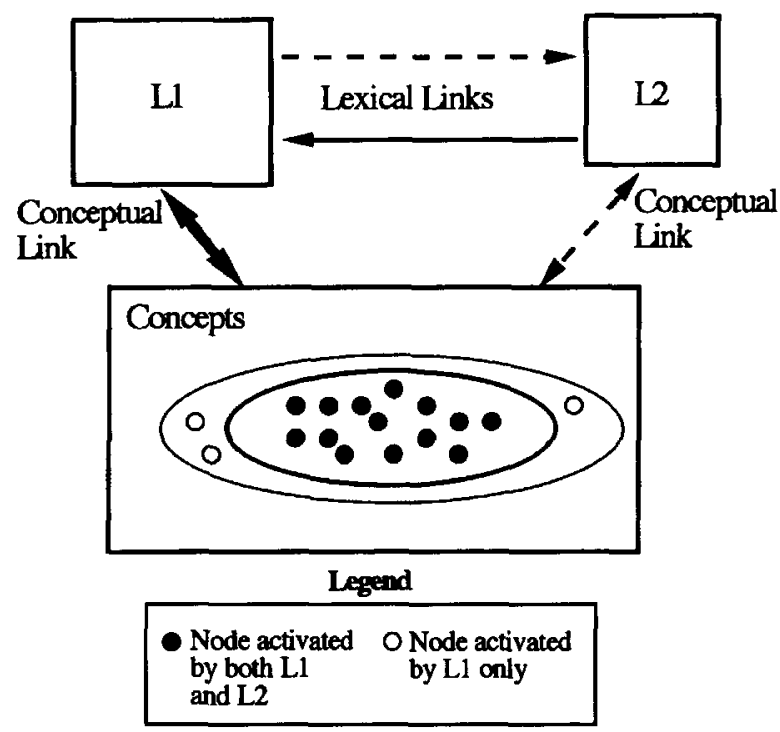

Less Fluent Bilingual's Representation
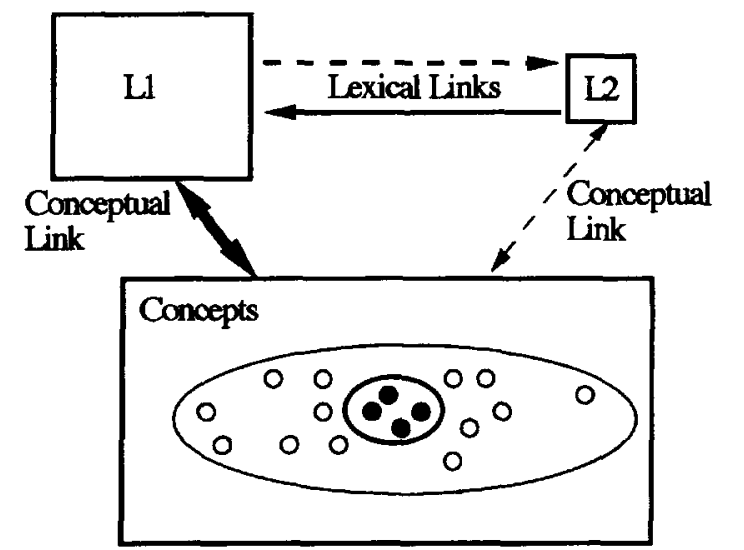

Figure 4. Schematic illustration of conceptual representation for bilinguals at different levels of $L 2$ proficiency. The top illustration shows the hypothesized conceptual representation for more-fluent bilinguals. The bottom illustration shows the hypothesized conceptual representation for less-fluent bilinguals. The dashed lines stand for weaker comnections, and the thick solid lines stand for very strong connections. The large set represents a category activated by L1, and the small set represents the same category but activated by $L 2$.

are also associated with L1, when English target words are presented. Finally, the English-English condition is optimal because there is a complete match between the conceptual and lexical representations.

A proposal similar to the one we have offered has been described by Dagenbach, Carr, and Barnhardt (1990) to account for inhibitory effects in semantic priming for newly learned vocabulary words. They reported that new vocabulary words that can be recognized but not recalled following a brief training session produced inhibitory rather that facilitatory semantic priming effects in lexical decision. Dagenbach et al. (1990) hypothesized that
At low levels of learning, codes representing new material are weakly established and hence only weakly activatable. Attempts to incorporate new information into existing semantic structures or attempts to search for it later after its initial incorporation might be hindered by related concepts or facts having greater activation, because of their relatively greater strength and higher potential activability. (p. 337)

The mechanism that we have described may thus represent a specific instance (in the case of learning secondlanguage words) of a more general mechanism for learning new connections in semantic or conceptual memory.

The analysis that we have presented suggests that conceptual mediation of L 2 can be achieved even by lessfluent bilinguals. This conclusion is superficially at odds with the claims of previous studies that less-fluent bilinguals rely on word association or lexical mediation between L1 and L2 (e.g., Chen \& Ho, 1986; Chen \& Leung, 1989; Kroll \& Curley, 1988). A critical difference between the present study and the past research on this topic is that the categorization task does not require subjects to produce words in their second language. Previous tests of concept mediation versus word association have relied heavily on production measures such as picture naming, translation, and word naming. The results that we have presented for the less-fluent subjects suggest that they are able to use L2, in a restricted way, to access concepts. However, this limited access to concepts does not mean that they are capable of using concepts to retrieve $\mathrm{L} 2$ words for production. The additional processing costs observed in the English-French condition of the present study are likely to be representative of the problem that the early second-language learner faces when attempting to translate from L1 to L2. The first language activates a large set of concepts in memory, only a small subset of which correspond to words in L2 that the less-fluent subject knows. A central problem for the beginning second-language learner is thus to learn to effectively inhibit activation of the first language, and the difficulty in doing so will be most evident during production (Green, 1986).

\section{Conclusion}

In summary, in this experiment we have shown that relatively fluent bilinguals can use conceptual links effectively in within- and cross-language categorization. Less-fluent bilinguals appear to be able to rely on their "weaker" L2 conceptual link but only in within-language categorization. These results suggest that the amount or type of activation from the L2 lexicon to the conceptual representations may promote patterns of conceptual activation that are different from those provided by the L1 lexicon. Hence, although both languages may access some shared conceptual information, each language may also initially promote a distinct pattern of conceptual activation. We believe that the approach that we have described provides a constructive method for analyzing not only the end state of second-language learning, but also for understanding the changes in mental represen- 
tation that characterize the development of second-language fluency.

\section{REFERENCES}

Al TARRIBA, J. (1990). Constraints on interlingual facilitation effects in priming in Spanish-English bilinguals. Unpublished dissertation, Vanderbilt University.

Balota, D. A., \& Chumbley, J. I. (1984). Are lexical decisions a good measure of lexical access? The role of word frequency in the neglected decision stage. Journal of Experimental Psychology: Human Perception \& Performance, 10, 340-357.

Caramazza, A., \& Brones, I. (1980). Semantic classification by bilinguals. Canadian Journal of Psychology, 34, 77-81.

CHEN, H.-C., \& Ho, C. (1986). Development of Stroop interference in Chinese-English bilinguals. Journal of Experimental Psychology: Learning, Memory, \& Cognition, 12, 397-401.

Chen, H.-C., \& Leung, Y.-S. (1989). Patterns of lexical processing in a nonnative language. Journal of Experimental Psychology: Learning, Memory, \& Cognition, 15, 316-325.

Dagenbach, D., Carr, T., \& BarnhardT, T. (1990). Inhibitory semantic priming of lexical decisions due to failure to retrieve weakly activated codes. Journal of Experimental Psychology: Learning. Memory, \& Cognition, 16, 328-340.

DE GROOT, A. M. B. (1992). Determinants of word translation. Journal of Experimental Psychology. Learning, Memory, \& Cognition, 18, $1001-1018$.

DE GROOT, A. M. B. (1993). Word-type effects in bilingual processing tasks: Support for a mixed representational system. In R. Schreuder \& B. Weltens (Eds.), The bilingual lexicon (pp. 27-51). Philadelphia: John Benjamin.

de Groot, A. M. B., Dannenburg, L., \& van Hell, J. G. (1994), Forward and backward word translation. Journal of Memory \& Language, 33, 600-629.

Durgunoglu, A. Y., \& Roediger, H. L., III (1987). Test differences in accessing bilingual memory. Journal of Memory \& Language, 26, $377-391$.

FRANCIS, W. N., \& KUČERA, H. (1982). Frequency analysis of English usage. Providence, RI: Brown University Press.

GraingER, J., \& BeAUVILLAIN, C. (1987). Language blocking and lexical access in bilinguals. Quarterly Journal of Experimental Psychology, 39A, 295-319.

GraingER, J., \& O'REAGAN, K. (1992). A psychophysical investigation of language priming effect in two English-French bilinguals. European Journal of Cognitive Psychology, 23, 323-339.

GreEN, D. W. (1986). Control, activation, and resource: A framework and a model for the control of speech in bilinguals. Brain \& Language, 27, 210-223.

HINEs, T. (1993). Persistent slowing of responses to words in the nonnative language. Unpublished manuscript.

JoB, R., RUMIATI, R., \& LotTo, L. (1992). The picture superiority effect in categorization: Visual or semantic? Journal of Experimental Psychology: Learning, Memory, \& Cognition, 18, 1019-1028.

Keatley, C. W., Spinks, J. A., \& de Gelder, B. (1994). Asymmetrical cross-language priming effects. Memory \& Cognition, 22, 70-84.

KIRK, R. E. (1982). Experimental design: Procedures for the behavioral sciences. Belmont, CA: Brooks/Cole.

KROLL, J. F. (1993). Accessing conceptual representation for words in a second language. In R. Schreuder \& B. Weltens (Eds.), The bilingual lexicon (pp. 53-81). Philadelphia: John Benjamin.

Kroll, J. F., \& CURLEY, J. (1988). Lexical memory in novice bilinguals: The role of concepts in retrieving second language words. In M. Gruneberg, P. Morris, \& R. Sykes (Eds.), Practical aspects of memory (Vol. 2, pp. 389-395). London: Wiley.

Kroll, J. F, Dufour, R., Sholl, A., \& RoufCA, P. (1993, June). The role of concept mediation in acquiring a second language. Poster presented at the meeting of the American Psychological Society, Chicago.

KROLL, J. F., \& SHOLL, A. (1992). Lexical and conceptual memory in fluent and nonfluent bilinguals. In R. J. Harris (Ed.), Cognitive processing in bilinguals (pp. 191-204). Amsterdam: Elsevier.
Kroll, J. F., Sholl, A., Altarriba, J., Luppino, C., Moynihan, L., \& SANDERS, C. (1992, November). Cross-languages semantic priming: Evidence for independent lexical and conceptual contributions. Paper presented at the meeting of the Psychonomic Society, St. Louis.

Kroll, J. F., \& StewarT, E. (1990, November). Concept mediation in bilingual translation. Paper presented at the meetıng of the Psychonomic Society, New Orleans.

Kroll, J. F., \& STEWART, E. (1994). Category interference in translation and picture naming: Evidence for asymmetric connections between bilingual memory representations. Journal of Memory \& Language, 33, 149-174.

NEELY, J. H. (1990). Semantic primıng effects in visual word recognition: A selective review of current findings and theories. In D. Besner \& G. Humphreys (Eds.), Basic processes in reading : Visual word recognition (pp. 264-336). Hillsdale, NJ. Erlbaum.

PotTer, M. C., \& FAulConer, B. A. (1975). Time to understand pictures and words. Nature, 253, 437-438.

Potter, M. C., So, K.-F., von Eckhardt, B., \& Feldman, L. B. (1984). Lexical and conceptual representation in beginning and more proficient bilinguals. Journal of Verbal Learning \& Verbal Behavior, 23, 23-38.

Rosch, E. (1975). Cognitive representations of semantic categories. Journal of Experimental Psychology. General, 104, 192-233.

RoufCA, P. (1992). A longitudinal study of second language acquisition in French. Unpublished manuscript, Mount Holyoke College, Department of Psychology \& Education.

Sánchez-Casas, R. M., Davis, C. W., \& García-Albea, J. E. (1992). Bilingual lexical processing: Exploring the cognate-noncognate distinction. European Journal of Cognitive Psychology, 23, 293-310.

SeidenberG, M. S., Waters, G. S., SANDERs, M., \& Langer, P. (1984). Pre- and postlexical loci of contextual effects on word recognition. Memory \& Cognition, 12, 315-328.

SHANON, B. (1982). Identification and classification of words and drawings in two languages. Quarterly Journal of Experimental Psychology, 34A, 135-152.

SHOLL, A. (1993). Memory performance following bilingual translation: Lexical and conceptual determinants of cross-language transfer. Unpublished master's thesis, University of Massachusetts.

Sholl, A., Kroll, J. F., \& Sankaranarayanan, A. (1993, November). Transfer between picture naming and translation: $A$ test of asymmetries in bilingual memory. Poster presented at the meeting of the Psychonomic Society, Washington, DC

SiPle, P., Walls, W. F., \& Miller, C. (1985, November). Visual similarity and semantic activation by pictures and words. Paper presented at the meeting of the Psychonomic Society, Boston.

SMith, E. E., Shoben, E. J., \& RiPS, L. J. (1974). Structure and process in semantic memory: A featural model for semantic decisions. Psychological Review, 81, 214-241.

SNODGRASs, J. G. (1984). Concepts and their surface representations. Journal of Verbal Learning \& Verbal Behavior, 23, 3-22.

Talamas, A., \& Kroll, J. F. (1993, February). Form related errors in second language learning: A preliminary stage in the acquisition of $L 2$ vocabulary. Paper presented at the Conference on Second Language Acquisition and Foreign Language Learning, Purdue University.

Tzelgov, J., \& Eben-Ezra, S. (1992). Components of the betweenlanguage semantic prıming effect. European Journal of Cognitive Psychology, 4, 253-272.

\section{NOTES}

1. We will use the term bilingual to refer generally to any individual who is in the process of learning a second language and who has achieved some level of fluency. In the present study we will describe two subject populations, one less fluent and the other more fluent in French. Technically, neither group of subjects is bilingual in that they are dominant in English and even the more-fluent subjects are far from having near-native fluency in L2. Because our interest is in the process of how individuals acquire L2 proficiency, what is important for our purposes is not whether the more-fluent subjects are balanced bilinguals, but rather whether they have passed beyond an early critical stage of second-language acquisition. 
2. There are a few recent reports of conditions under which a translation asymmetry has not been found. In a set of experiments on translation performance, de Groot, Dannenburg, and van Hell (1994) reported the asymmetry for noncognate translation equivalents, but not for cognates. Likewise, they found the asymmetry for abstract but not for concrete words. Sholl, Kroll, and Sankaranarayanan (1993), using pictureable nouns, found the asymmetry in translation when words were translated for the first time, but not when they were translated following the presentation of the concept in a picture naming task.

3 . The number of years of experience with L2 reflected the number of years in which courses in L2 were taken and subtracting "the number of years experience with L2" from the subject's "age" does not result in the age at which the subjects began learning L2.

4. Because SOA did not interact with any other factors in the overall "yes" analyses, it was ignored in the post hoc analysis.

\section{APPENDIX}

Lists, in alphabetical order, of the test categories, target words, and their respective word frequencies and typicality ratings used in the experiment. The word frequencies are the number of times per million in printed English taken from the Francis and Kučera (1982) word count. The typicality ratings are the mean ratings on a seven-point scale (where " 1 " is highly typical and "7" is atypical) from Rosch (1975).

\begin{tabular}{llccc} 
English & French & $\begin{array}{c}\text { Cognate } \\
\text { Status }\end{array}$ & $\begin{array}{c}\text { Word } \\
\text { Frequency }\end{array}$ & $\begin{array}{c}\text { Typicality } \\
\text { Rating }\end{array}$ \\
\hline
\end{tabular}

$\begin{array}{lll}\text { Bird/Oiseau } & & \\ \text { canary } & \text { canarie } & \text { cognate } \\ \text { cardinal } & \text { cardinal } & \text { cognate } \\ \text { crane } & \text { grue } & \text { non-cog } \\ \text { dove } & \text { colombe } & \text { non-cog } \\ \text { eagle } & \text { aigle } & \text { non-cog } \\ \text { hawk } & \text { faucon } & \text { non-cog } \\ \text { lark } & \text { alouette } & \text { non-cog } \\ \text { parakeet } & \text { perruche } & \text { non-cog } \\ \text { parrot } & \text { perroquet } & \text { non-cog } \\ \text { pigeon } & \text { pigeon } & \text { cognate } \\ \text { raven } & \text { corbeau } & \text { non-cog } \\ \text { seagull } & \text { mouette } & \text { non-cog } \\ \text { sparrow } & \text { moineau } & \text { non-cog } \\ \text { starling } & \text { étourneau } & \text { non-cog } \\ \text { swallow } & \text { hirondelle } & \text { non-cog } \\ \text { thrush } & \text { grive } & \text { non-cog }\end{array}$

Clothing/Vêtement

$\begin{array}{lllrl}\text { blouse } & \text { blouse } & \text { cognate } & 1 & 1.27 \\ \text { coat } & \text { manteau } & \text { non-cog } & 43 & 1.88 \\ \text { dress } & \text { robe } & \text { non-cog } & 67 & 1.14 \\ \text { jacket } & \text { veston } & \text { non-cog } & 33 & 1.68 \\ \text { overcoat } & \text { paletot } & \text { non-cog } & 5 & 2.29 \\ \text { pajamas } & \text { pyjama } & \text { cognate } & 3 & 2.25 \\ \text { panties } & \text { culotte } & \text { non-cog } & 1 & 2.08 \\ \text { pants } & \text { pantalon } & \text { non-cog } & 9 & 1.12 \\ \text { parka } & \text { parka } & \text { cognate } & 0 & 2.19 \\ \text { raincoat } & \text { imperméable } & \text { non-cog } & 2 & 2.44 \\ \text { shirt } & \text { chemise } & \text { non-cog } & 27 & 1.14 \\ \text { skirt } & \text { jupe } & \text { non-cog } & 21 & 1.21 \\ \text { stocking } & \text { bas } & \text { non-cog } & 5 & 2.79 \\ \text { suit } & \text { habit } & \text { non-cog } & 48 & 1.45 \\ \text { sweater } & \text { tricot } & \text { non-cog } & 14 & 1.89 \\ \text { sweatshirt } & \text { chandail } & \text { non-cog } & 2 & 1.95 \\ & & & & \\ \text { Fruit'Fruit } & & & & 1.08 \\ \text { apple } & \text { pomme } & \text { non-cog } & 15 & 1.36 \\ \text { apricot } & \text { abricot } & \text { cognate } & 1 & \end{array}$

APPENDIX (Continued)

\begin{tabular}{lllllr}
\cline { 5 - 6 } \multicolumn{1}{c}{ English } & \multicolumn{1}{c}{ French } & & $\begin{array}{c}\text { Cognate } \\
\text { Status }\end{array}$ & $\begin{array}{c}\text { Word } \\
\text { Frequency }\end{array}$ & $\begin{array}{c}\text { Typicality } \\
\text { Rating }\end{array}$ \\
\cline { 6 - 7 } banana & banane & & cognate & 5 & 1.15 \\
blueberry & bleuet & & non-cog & 2 & 2.14 \\
cherry & cerise & & non-cog & 6 & 1.86 \\
grapes & raisins & & cognate & 10 & 1.38 \\
lemon & citron & & cognate & 16 & 2.16 \\
nectarine & nectarine & cognate & 0 & 1.52 \\
orange & orange & & cognate & 15 & 1.07 \\
peach & peche & & non-cog & 4 & 1.17 \\
pear & poire & & non-cog & 8 & 1.18 \\
pineapple & ananas & & non-cog & 9 & 1.91 \\
plum & prune & cognate & 1 & 1.67 \\
raspberry & framboise & non-cog & 1 & 2.15 \\
strawberry & fraise & non-cog & 2 & 1.61 \\
tangerine & tangerine & cognate & 0 & 1.36
\end{tabular}

Furniture/Meuble

\begin{tabular}{|c|c|c|c|c|}
\hline bed & lit & non-cog & 139 & 1.58 \\
\hline bench & banc & non-cog & 42 & 2.77 \\
\hline bookcase & bibliothèque & cognate & 3 & 2.15 \\
\hline buffet & buffet & cognate & 6 & 2.89 \\
\hline bureau & bureau & cognate & 44 & 1.49 \\
\hline cabinet & cabinet & cognate & 22 & 2.49 \\
\hline chair & chaise & non-cog & 89 & 1.04 \\
\hline chest & coffre & non-cog & 57 & 1.98 \\
\hline couch & canapé & cognate & 13 & 1.10 \\
\hline divan & divan & non-cog & 7 & 1.70 \\
\hline dresser & commode & non-cog & 3 & 1.37 \\
\hline $\operatorname{lamp}$ & lampe & cognate & 24 & 2.94 \\
\hline rocker & berceuse & non-cog & 2 & 1.42 \\
\hline sofa & sofa & cognate & 9 & 1.04 \\
\hline table & table & cognate & 242 & 1.10 \\
\hline vanity & vanitée & non-cog & 8 & 2.13 \\
\hline \multicolumn{5}{|l|}{ Tool/Outil } \\
\hline chisel & ciseau & non-cog & 4 & 2.26 \\
\hline drill & perceuse & non-cog & 33 & 1.59 \\
\hline file & lime & non-cog & 81 & 2.01 \\
\hline hammer & marteau & non-cog & 9 & 1.34 \\
\hline ladder & échelle & non-cog & 19 & 2.64 \\
\hline level & niveau & non-cog & 213 & 1.82 \\
\hline nail & clou & non-cog & 14 & 1.67 \\
\hline pencil & crayon & cognate & 34 & 2.39 \\
\hline plier & pince & non-cog & 1 & 2.59 \\
\hline ruler & règle & non-cog & 3 & 1.48 \\
\hline sander & sableuse & non-cog & 1 & 1.79 \\
\hline saw & scie & non-cog & 8 & 1.04 \\
\hline sawhorse & chevalet & non-cog & 1 & 1.77 \\
\hline screwdriver & tournevis & non-cog & 0 & 1.56 \\
\hline screws & vis & non-cog & 21 & 2.77 \\
\hline square & équerre & non-cog & 143 & 2.44 \\
\hline
\end{tabular}

Vegetable/Légume

$\begin{array}{lllrl}\text { asparagus } & \text { asperge } & \text { cognate } & 1 & 1.41 \\ \text { bean } & \text { fève } & \text { non-cog } & 13 & 2.54 \\ \text { broccoli } & \text { broccoli } & \text { cognate } & 4 & 1.28 \\ \text { carrot } & \text { carotte } & \text { cognate } & 5 & 1.15 \\ \text { celery } & \text { célerie } & \text { cognate } & 4 & 1.90 \\ \text { corn } & \text { mais } & \text { non-cog } & 38 & 1.55 \\ \text { cucumber } & \text { cocombre } & \text { cognate } & 0 & 2.05 \\ \text { eggplant } & \text { aubergine } & \text { non-cog } & 0 & 2.38 \\ \text { lettuce } & \text { laitue } & \text { non-cog } & 0 & 1.85 \\ \text { onions } & \text { oignons } & \text { cognate } & 19 & 2.52 \\ \text { peas } & \text { pois } & \text { non-cog } & 24 & 1.07 \\ \text { radish } & \text { radis } & \text { non-cog } & 8 & 2.51 \\ \text { squash } & \text { courge } & \text { non-cog } & 2 & 1.83 \\ \text { spinach } & \text { épinard } & \text { non-cog } & 2 & 1.22\end{array}$




\section{APPENDIX (Continued)}

\begin{tabular}{|c|c|c|c|c|}
\hline English & French & $\begin{array}{c}\text { Cognate } \\
\text { Status }\end{array}$ & $\begin{array}{c}\text { Word } \\
\text { Frequency }\end{array}$ & $\begin{array}{c}\text { Typicality } \\
\text { Rating }\end{array}$ \\
\hline & tomate & cognate & 7 & 2.23 \\
\hline urnip & navet & non-cog & 1 & 2.37 \\
\hline
\end{tabular}

Vehicle/Véhicule

\begin{tabular}{|c|c|c|}
\hline airplane & avion & non-cog \\
\hline ambulance & ambulance & cognate \\
\hline automobile & automobile & cognat \\
\hline & bicyclette & cognate \\
\hline boat & bateau & non-cog \\
\hline bus & autobus & cognate \\
\hline carriage & voiture & non-cog \\
\hline ep & jeep & cognate \\
\hline J & jet & cognate \\
\hline motorcycle & motocyclette & cognate \\
\hline eetcar & tramway & non-cog \\
\hline & $\operatorname{taxi}$ & cognate \\
\hline & train & cognate \\
\hline & chariot & non-cog \\
\hline & camion & non-cog \\
\hline
\end{tabular}

\begin{tabular}{|c|c|c|c|c|}
\hline \multirow[b]{2}{*}{ _Englısh } & \multicolumn{3}{|c|}{ APPENDLX (Continued) } & \multirow[b]{2}{*}{$\begin{array}{c}\text { Typicality } \\
\text { Ratıng }\end{array}$} \\
\hline & French & $\begin{array}{c}\text { Cognate } \\
\text { Status } \\
\end{array}$ & $\begin{array}{c}\text { Word } \\
\text { Frequency }\end{array}$ & \\
\hline van & wagonnette & cognate & 32 & 1.95 \\
\hline \multicolumn{5}{|c|}{ Weapon/Arme } \\
\hline arrow & flêche & non-cog & 20 & 2.66 \\
\hline bayonet & bayonette & cognate & 9 & 1.69 \\
\hline bazooka & bazooka & cognate & 0 & 176 \\
\hline bomb & bombe & cognate & 68 & 1.61 \\
\hline bullet & balle & non-cog & 49 & 244 \\
\hline cannon & canon & cognate & 4 & 1.96 \\
\hline club & bâton & non-cog & 69 & 2.09 \\
\hline dagger & poignard & non-cog & 1 & 1.41 \\
\hline grenade & grenade & non-cog & 9 & 1.61 \\
\hline gun & fusil & non-cog & 142 & 1.02 \\
\hline spear & lance & non-cog & 5 & 2.14 \\
\hline mortar & mortier & non-cog & 13 & 2.56 \\
\hline pistol & pistolet & cognate & 31 & 1.07 \\
\hline revolver & revolver & cognate & 14 & 1.09 \\
\hline rifle & carabine & non-cog & 87 & 1.17 \\
\hline sword & épée & non-cog & 12 & 1.47 \\
\hline
\end{tabular}

(Manuscript received February 9, 1994; revision accepted for publication May 25, 1994.) 